RESEARCH ARTICLE

\title{
Streptococcus pneumoniae acquisition among vaccinated Malaysian hajj pilgrims and its associated factors
}

\author{
Nabilah Ismail ${ }^{1}$, Nur Adlina Zainuddin ${ }^{1}$, Zakuan Zainy Deris ${ }^{1}$, Zaidah Abdul Rahman ${ }^{1}$, Zeehaida \\ Mohamed ${ }^{1}$, Azian Harun ${ }^{1}$, Siti Suraiya Md Noor ${ }^{1}$, Nyi Nyi Naing ${ }^{2}$, Aniza Abd. Aziz ${ }^{3}$, Habsah Hasan ${ }^{1}$ \\ ${ }^{1}$ Department of Medical Microbiology and Parasitology, ${ }^{2}$ Unit of Biostatistics and Research Methodology, School of \\ Medical Sciences, Universiti Sains Malaysia, Kubang Kerian, Kelantan, ${ }^{3}$ Faculty of Medical and Health Sciences, \\ Universiti Sultan Zainal Abidin, Gong Badak, Kuala Terengganu, Terengganu, Malaysia
}

\section{ABSTRACT}

Objective: To describe the acquisition of Streptococcus pneumoniae among Malaysian hajj pilgrims and to determine the association with pneumococcal vaccination and respiratory symptoms.

Methods: This was a cross sectional study performed on Malaysian hajj pilgrims in a mass ritual gathering event from October to November 2013 in Makkah. Demographic data and associated factors for the respiratory infection were obtained by interview at Kota Bharu airport on their return. A sputum specimen or throat swab was taken from all subjects for $S$. pneumoniae culture and antimicrobial susceptibility testing.

Results: S. pneumoniae was isolated in $1.81 \%(n=10,95 \% \mathrm{Cl} 0.69,2.93)$ out of 549 subjects. Fifty percent of them $(n=5)$ had received pneumococcal vaccination. Difficulty in breathing was significantly reduced in subjects without $S$. pneumoniae isolation ( $\mathrm{p}=0.042$ ). In multivariable analysis, the uptake of pneumococcal vaccination was found to be statistically significant in reducing $S$. pneumoniae acquisition $(p=0.018)$ and those at a younger age were more liable to acquire colonization or infection $(p=0.018)$. Runny nose was significantly associated with the vaccinated group $(p=0.040)$.

Conclusion: The acquisition of $S$. pneumoniae among Malaysian hajj pilgrims in 2013 was significantly low with the uptake of pneumococcal vaccination. J Microbiol Infect Dis 2017; 7(2):56-62

Keywords: Streptococcus pneumoniae, vaccinated, Malaysian, haij pilgrims, associated factors

\section{INTRODUCTION}

Pneumonia has been identified as the leading cause of hospital admission during haji [1]. The rituals of hajj pilgrims had exposed a large number of people from all over the world in a certain period of time to various infectious agents. Overcrowding situations was a risk factor for transmission of infections especially for organisms that were transmitted via airborne and droplets. Streptococcus pneumoniae was among the most common organism isolated from respiratory tract among haij pilgrims with respiratory tract infections [2]. In a recent study, almost $20 \%$ of pilgrims had acquired $S$. pneumoniae nasal colonization post hajj [3].

Generally, adults with certain medical conditions are at highest risk for pneumococcal infection.
Those include exceeding age of 65 years old, those with comorbid illnesses such as chronic cardiovascular diseases, chronic pulmonary diseases, chronic liver diseases and diabetes mellitus. The latter was often associated with cardiovascular or renal dysfunction, which increases the risk for severe pneumococcal illness [5].

The data on susceptibility patterns of $S$. pneumoniae in hajj pilgrims is limited. The resistance rate of $S$. pneumoniae against many antimicrobial agents was high [6]. In the United States, the penicillin-resistant $S$. pneumoniae rate had increased from $5.6 \%$ in 1991 to $20.4 \%$ in 2001 [7]. However, a surveillance study in the United States in the year 2012 showed a lower resistant rate of $2.8 \%$ of invasive isolates of $S$.

Correspondence: Nabilah Ismail, Department of Medical Microbiology and Parasitology, School of Medical Sciences, Universiti Sains Malaysia, Kubang Kerian, Kelantan, Malaysia, E-mail: drnabilah@usm.my Received: 23 July 2016, Accepted: 08 January 2017

Copyright (C JMID / Journal of Microbiology and Infectious Diseases 2017, All rights reserved 
pneumoniae [8]. In Asian countries, prevalence rates of penicillin resistance were $0.7 \%$ and $57.5 \%$ in non-meningeal and meningeal isolates respectively [9]. This study also reported an alarming increase for erythromycin resistant $S$. pneumoniae in $72.7 \%$ followed by $69.7 \%$, and $68.9 \%$ for azithromycin and clarithromycin resistance respectively. Erythromycin resistance was more frequently found in children $(<5$ years old; $44.8 \%$ ) than in adults ( $\geq 65$ years old; $25.1 \%$ ) (OR, 2.9; $95 \% \mathrm{Cl}, 2.2$ to 3.8; $p<0.0001$ ).

Although pneumococcal vaccination was shown to be effective in preventing pneumococcal infections [10], this vaccine is currently not a mandatory requirement for hajj pilgrimage leading to low uptakes of pneumococcal vaccine among hajj pilgrims, even in developed countries [3, 11]. However, adults and high risk pilgrims were recommended by the Malaysian government to take a single dose of pneumococcal vaccine prior to travelling for hajj [12]. Two types of vaccines were available in Malaysia, which are Pneumococcal Conjugate Vaccine 13 (PCV 13) or Pneumococcal Polysaccharide Vaccine 23 (PPV 23). PCV 13 is a pediatric vaccine available on the market and offers broader protection against 10 and 13 serotypes. PPV 23 protects against 23 pneumococcal serotypes and is recommended for use, mainly in adults.

Thus, the aim of this study was to describe the prevalence of $S$. pneumoniae respiratory acquisition among Malaysian hajj pilgrims in 2013, to determine its associated factors and also to make a comparison between vaccination status with regards to pneumococcal acquisition and respiratory symptoms.

\section{METHODS}

\section{Study design}

This was a cross sectional study performed on returning Malaysian hajj pilgrims commencing from October to November 2013. Data and sample collection were performed on studied subjects at Sultan Ismail Petra Airport (SIPA), Kota Bharu, Kelantan, Malaysia. Sampling was performed using a simple random sampling method.

\section{Sultan Ismail Petra Airport}

This airport is one of the busiest domestic airports in Malaysia during the Hajj season with approximately 2000 passengers per Hajj season. It receives passengers from Kuala Lumpur International Airport (KLIA) which comprises of pilgrims and ordinary passengers. The pilgrims had one or two days transit in KLIA from the Kingdom of Saudi Arabia (KSA) before arrival at SIPA.

\section{Data collection}

Demographic data, co-morbid illnesses and symptoms of respiratory infection were obtained through interviewer guided questionnaires at the airport on their return.

\section{Culture and antimicrobial susceptibility testing}

A sputum specimen and a throat swab were taken from each subject for culture and antimicrobial susceptibility testing (AST). The sputum was placed in a sterile plastic container. Throat swabs were transported in Amies media. Upon receiving them at the Microbiology Laboratory, Universiti Sains Malaysia, both specimens were cultured immediately on blood agar and optochin disc was added to isolate $S$. pneumoniae. The procedure for culturing and identification of organisms was according to standard microbiology laboratory protocols. AST against erythromycin, oxacillin, vancomycin and trimethoprim-sulfamethoxazole was performed using the disc diffusion method and was interpreted according to the Clinical and Laboratory Standards Institute [13].

\section{Data analysis}

Data were analyzed and presented as descriptive statistics. The associated factors such as the demographic data, pneumococcal vaccination and co-morbid illnesses with pneumococcal acquisition were analyzed using multiple logistic regressions. The potential risk factors with $p<0.25$ in univariate analysis proceeded to multiple logistic regression models for multivariable analysis of numerical and categorical variables like gender, presence of co-morbid illnesses and pneumococcal vaccine uptake.

\section{Ethical approval}

Ethical approval was obtained from the Human Research Ethics Committee, Universiti Sains 
Malaysia (USMKK/PPP/JEPeM (266.3 (3)) prior to conducting the study. Written consent was obtained from the subjects upon enrolment into the study.

\section{RESULTS}

\section{Demographic data}

A total of 551 subjects agreed to participate in the study. However, some of the data were incomplete due to brief contact during the interview session. The interview sessions were conducted in a short period while pilgrims were waiting for their luggage. Thus, the total subjects for each variable analyzed varied. The mean age of the subjects was $54.07 \pm 10.36$ years ( $n=$ $522)$, male were $47.2 \%(n=255$ out of 540$)$ and $79.3 \%(n=388$ out of $489,95 \% \mathrm{Cl})$ received pneumococcal vaccination.

\section{Associated factors of $S$. pneumoniae acquisition}

S. pneumoniae was isolated in $1.81 \% \quad(n=10$, $95 \% \mathrm{Cl} 0.69,2.93$ ) out of 549 subjects. Eight out of 10 subjects were symptomatic for respiratory infection such as cough $(n=8)$ and runny nose $(n=6)$. Two out of the 10 subjects had influenza like illness (ILI) symptoms (fever, cough and runny nose).

Table 1. Associated factors for acquisition of Streptococcus pneumoniae.

\begin{tabular}{|c|c|c|c|c|c|c|c|c|}
\hline \multirow{2}{*}{$\begin{array}{l}\text { Variables ( } n \text {, total } \\
\text { analyzed) }\end{array}$} & \multicolumn{2}{|c|}{$\begin{array}{c}\text { Acquisition of Streptococcus } \\
\text { pneumoniae }\end{array}$} & \multicolumn{3}{|c|}{ Univariate } & \multicolumn{3}{|c|}{ Multivariate } \\
\hline & $\begin{array}{l}\text { Yes, } \mathbf{n}(\%) \text { or } \\
\text { mean (SD) }\end{array}$ & $\begin{array}{l}\text { No, } n(\%) \text { or } \\
\text { mean (SD) }\end{array}$ & $\begin{array}{l}\text { OR }(95 \% \\
\quad \mathrm{Cl})\end{array}$ & Wald & $\begin{array}{c}\mathrm{p}- \\
\text { value }\end{array}$ & $\begin{array}{l}\text { OR }(95 \% \\
\text { Cl) }\end{array}$ & Wald & $\begin{array}{c}p- \\
\text { value }\end{array}$ \\
\hline $\mathrm{Age}^{\star}(549)$ & $48.78(16.47)$ & $54.08(10.22)$ & $\begin{array}{c}0.95(0.90- \\
1.01)\end{array}$ & 2.38 & 0.123 & $\begin{array}{l}0.91,(0.85- \\
0.99)\end{array}$ & 5.56 & 0.018 \\
\hline Gender (M) (540) & $3(30.0)$ & $252(47.5)$ & $\begin{array}{c}0.47(0.12- \\
1.85)\end{array}$ & 1.16 & 0.281 & - & - & - \\
\hline $\begin{array}{l}\text { Pneumococcal } \\
\text { vaccination (489) }\end{array}$ & $5(55.6)$ & $383(79.8)$ & $\begin{array}{c}0.32(0.08- \\
1.20)\end{array}$ & 2.86 & 0.091 & $\begin{array}{l}0.16(0.04- \\
0.73)\end{array}$ & 5.63 & 0.018 \\
\hline Cough (540) & $8(80.0)$ & $403(76.0)$ & $\begin{array}{c}1.26(0.26- \\
6.01)\end{array}$ & 0.08 & 0.771 & - & - & \\
\hline Runny nose (540) & $6(60.0)$ & $221(41.7)$ & $\begin{array}{c}2.10(0.59- \\
7.52)\end{array}$ & 1.29 & 0.256 & - & - & \\
\hline ILI (541) & $2(20.0)$ & $88(16.6)$ & $\begin{array}{l}1.26(0.26- \\
6.03\end{array}$ & 0.08 & 0.774 & - & - & \\
\hline $\begin{array}{l}\text { Difficulty in Breathing } \\
\text { (541) }\end{array}$ & $2(20.0)$ & $24(4.5)$ & $\begin{array}{c}5.28(1.06- \\
26.23)\end{array}$ & 4.14 & 0.042 & $\begin{array}{c}13.50(2.16- \\
84.24)\end{array}$ & 7.76 & 0.005 \\
\hline Myalgia (539) & $3(30.0)$ & $74(14.0)$ & $\begin{array}{c}2.64(0.67- \\
10.42)\end{array}$ & 1.91 & 0.167 & - & - & \\
\hline Diabetes (541) & $0(0.0)$ & $77(14.5)$ & - & - & 0.997 & - & - & \\
\hline COAD (541) & $0(0.0)$ & $2(0.4)$ & - & - & 1.000 & - & - & \\
\hline Asthma (541) & $0(0.0)$ & $17(3.2)$ & - & - & 0.999 & - & - & \\
\hline Smoking (541) & $0(0.0)$ & $26(4.9)$ & - & - & 0.998 & - & - & \\
\hline $\begin{array}{l}\text { Chronic renal disease } \\
(541)\end{array}$ & $0(0.0)$ & $6(1.1)$ & - & - & 0.999 & - & - & \\
\hline $\begin{array}{l}\text { Chronic heart disease } \\
\text { (541) }\end{array}$ & $1(10.0)$ & $16(3.0)$ & $\begin{array}{l}3.58(0.43- \\
29.95) \\
\end{array}$ & 1.38 & 0.240 & - & - & \\
\hline
\end{tabular}


Table 2. Comparison of respiratory symptoms between pneumococcal vaccinated and non-vaccinated group.

\begin{tabular}{|c|c|c|c|c|c|c|c|c|}
\hline \multirow{2}{*}{$\begin{array}{l}\text { Variables ( } n \text {, total } \\
\text { analyzed) }\end{array}$} & \multicolumn{2}{|c|}{$\begin{array}{l}\text { Pneumococcal } \\
\text { vaccination }\end{array}$} & \multicolumn{3}{|c|}{ Univariate } & \multicolumn{3}{|c|}{ Multivariate } \\
\hline & Yes, n (\%) & No, n (\%) & OR $(95 \% \mathrm{Cl})$ & Wald & $\begin{array}{c}\mathrm{p}- \\
\text { value }\end{array}$ & OR $(95 \% \mathrm{Cl})$ & Wald & $\begin{array}{c}p- \\
\text { value }\end{array}$ \\
\hline Age (years, SD)* (475) & $\begin{array}{c}53.61 \\
(10.11)\end{array}$ & $\begin{array}{c}55.43 \\
(10.43)\end{array}$ & $\begin{array}{c}0.98(0.96 \\
1.01)\end{array}$ & 2.41 & 0.120 & - & - & - \\
\hline Male gender (498) & $186(47.2)$ & $45(43.3)$ & $\begin{array}{l}0.85(0.55 \\
1.32)\end{array}$ & 0.51 & 0.474 & - & - & - \\
\hline Cough (498) & $300(76.3)$ & $79(75.2)$ & $\begin{array}{c}1.06(0.64 \\
1.75)\end{array}$ & 0.06 & 0.815 & - & - & - \\
\hline Runny nose (498) & $153(38.8)$ & $52(50.0)$ & $\begin{array}{l}0.64(0.41 \\
0.98)\end{array}$ & 4.20 & 0.040 & $\begin{array}{c}0.64(0.41 \\
0.98)\end{array}$ & 4.20 & 0.040 \\
\hline $\mathrm{ILI}^{\ddagger}(499)$ & $60(15.2)$ & $19(18.1)$ & $\begin{array}{c}0.81(0.46 \\
1.44)\end{array}$ & 0.51 & 0.475 & - & - & - \\
\hline $\begin{array}{l}\text { Difficulty in Breathing } \\
\text { (499) }\end{array}$ & $19(4.8)$ & $6(5.7)$ & $\begin{array}{l}0.84(0.33 \\
2.15)\end{array}$ & 0.14 & 0.710 & $\begin{array}{c}0.92 \\
(0.36,2.39)\end{array}$ & 0.03 & 0.864 \\
\hline Myalgia (497) & $54(13.8)$ & $12(11.4)$ & $\begin{array}{c}1.24(0.64 \\
2.41)\end{array}$ & 0.40 & 0.530 & - & - & - \\
\hline
\end{tabular}

Table 3. Comparison of post-hajj Streptococcus pneumoniae acquisition among international hajj pilgrims.

\begin{tabular}{cccccccc}
\hline Study & $\begin{array}{c}\text { Country of } \\
\text { pilgrims }\end{array}$ & Year & Reference & $\begin{array}{c}\text { Total } \\
\text { samples } \\
\text { (pre-hajj } \\
\text { and post- } \\
\text { hajj) }\end{array}$ & $\begin{array}{c}\text { Method } \\
\text { used for } \\
\text { detection }\end{array}$ & $\begin{array}{c}\text { Pneumococcal } \\
\text { acquisition post- } \\
\text { hajj, } \mathbf{n}(\%)\end{array}$ & $\begin{array}{c}\text { Pneumococcal } \\
\text { vaccination, } \mathbf{n} \\
(\%)\end{array}$ \\
\hline 1 & Malaysia & 2013 & Our study & 549 & Culture & $10(1.81)$ & $388(79.0)$ \\
\hline 2 & $\begin{array}{c}\text { Multi- } \\
\text { countries }\end{array}$ & $\begin{array}{c}2011 \& \\
2012\end{array}$ & $\begin{array}{c}\text { Memish et al. } \\
\text { 2015 [2] }\end{array}$ & 3203 & Culture & $191(6.0)$ & $1782(61.1)^{*}$ \\
3 & French & 2012 & $\begin{array}{c}\text { Benkouiten et } \\
\text { al 2014 [3] }\end{array}$ & 169 & $\begin{array}{c}\text { Realtime } \\
\text { PCR }\end{array}$ & $30(19.5)$ & $47(35.9)$ \\
\hline 4 & French & 2013 & $\begin{array}{c}\text { Benkouiten et } \\
\text { al 2014 [4] }\end{array}$ & 255 & $\begin{array}{c}\text { Realtime } \\
\text { PCR }\end{array}$ & $29(36.3)$ & $66(51.2)$ \\
\hline
\end{tabular}

*Influenza or pneumococcal vaccination

Only one subject was asymptomatic possibly in a carrier state. In the univariable analysis, difficulty in breathing was significantly reduced in subjects without $S$. pneumonia isolation $(p$ $=0.042$ ) (Table 1). Five out of 10 subjects $(50 \%)$ with positive isolation of $S$. pneumoniae had received pneumococcal vaccination. The uptake of pneumococcal vaccination was found to be statistically significant in reducing pneumococcal acquisition $(p=0.018)$ and those who were younger had more tendencies to acquire colonization or infection $(p=0.018)$ (Table 1$)$.

\section{Associated factors of pneumococcal vaccination}

In the univariate analysis between pneumococcal vaccinated and non-vaccinated groups (Table 2), pilgrims who were vaccinated were significantly more likely than those who were unvaccinated to report (or to have) a runny nose ( $p=0.040)$. Other clinical symptoms such as ILI and difficulty in breathing were reduced in the vaccinated group, but they are not statistically significant.

\section{Antibiotic susceptibility pattern}

Only eight isolates were viable for antimicrobial susceptibility testing. The resistance rate of the isolates to penicillin, erythromycin and trimethoprim-sulfamethoxazole were $25 \%$, 
$37.5 \%$ and $50 \%$ respectively. The isolates showed $100 \%$ susceptibility to vancomycin.

\section{DISCUSSION}

Performing Hajj rituals is a risk factor for pneumococcal acquisition [2,14]. There is currently limited microbiological data regarding the prevalence and causes of respiratory infection during Hajj. In our study, we found that the prevalence of $S$. pneumoniae acquisition in Malaysian hajj pilgrims was very low (1.81\%) compared to previous studies that reported higher prevalence ranging from $4.8 \%$ to $53.8 \%$ [2,3,15-18].

The lower pneumococcal acquisition might be caused by several reasons. One of the possible reasons was the higher uptake of pneumococcal vaccination in this studied subjects $(n=388 / 79.0 \%)$ compared to other previous studies $(n=47 / 35.9 \%)$ [3] and $(n=66 / 51.2 \%)$ [4]. Pneumococcal vaccination had been proven to provide protection against $S$. pneumoniae infection [19]. The other reason could be the less sensitive method of isolation. The culture method had lower sensitivity compared to qPCR used in previous study [14].

In another study, PCR showed better sensitivity in detecting $S$. pneumoniae in patients who had been pretreated with antibiotics when culture methods came out as negative for this organism [20]. Thus, using culture methods to detect this organism in our study might have reflected the low prevalence of $S$. pneumoniae.

Furthermore, there is the probability that the majority of Malaysian hajj pilgrims had received antimicrobial agents whilst in KSA. Previous study has revealed that $58.8 \%$ of Malaysian hajj pilgrims received antimicrobial agents for upper respiratory tract infection [21]. Prior antimicrobial agent administration could have been one of the contributing factors for low isolation of $S$. pneumoniae in this study.

Among all the studied subjects, $38.2 \%$ had isolated Hemophilus influenzae. Out of 10 pilgrims who had $S$. pneumoniae isolated, only two had concurrent infection with $H$. influenzae, three had concurrent infections with other organisms and the rest had single isolation of $S$. pneumoniae. A previous study reported that the overgrowth of $H$. influenzae in the nasal cavity in the mouse model might suppress the growth of
$S$. pneumoniae [22]. Therefore, the low prevalence of $S$. pneumoniae acquisition in this study could be potentially due to overgrowth of $H$. influenzae.

In this study, those who were younger had more tendencies to acquire colonization or infection ( $p$ $=0.018$ ). This was thought that younger pilgrims were more active and more exposed to the extremely high density of the crowd during performing hajj rituals. However, gender was not associated with pneumococcal acquisition. In contrast to previous studies, pneumococcal infection could be acquired due to the tendency of smoking in males and subsequently having chronic obstructive airway disease [23]. Males also had a higher prevalence of chronic heart diseases which is also one of the risk factors for pneumococcal acquisition [5].

In this study, the uptake of pneumococcal vaccination was found to be statistically significant in reducing pneumococcal acquisition $(p=0.018)$. Compared to other similar studies on acquisition of $S$. pneumoniae in the vaccinated group among hajj pilgrims from other countries (Table 3 ), this study revealed a lower percentage of acquisition of $S$. pneumoniae with almost $80 \%$ of the vaccinated population $(p=$ 0.018) (Table 1). We postulated that our hajj pilgrims' population had achieved herd immunity in spite of our limitations in ascertaining strain serotyped and genotyped that was covered by pneumococcal vaccination. Benkouiten et al 2014 reported the increasing trend of $S$. pneumoniae acquisition in their study in 2013 compared to 2012 in spite of increased pneumococcal vaccination coverage of their hajj pilgrims' population [3]. We postulated that the herd immunity was not achieved in their hajj pilgrims' population.

In this study, the resistance rate of $S$. pneumoniae to penicillin, erythromycin and trimethoprim-sulfamethoxazole was $25 \%, 37.5 \%$ and $50 \%$ respectively. The results were comparable to a previous study which reported that resistant rates were $22 \%$ for penicillin; $35 \%$ for erythromycin, clarithromycin, and azithromycin; and $42 \%$ for cefaclor [6]. However, our resistance rate was much higher as compared to other previous studies conducted among Malaysian subjects in 1999. They discovered that the resistance rate to penicillin, 
erythromycin and trimethoprim-sulfamethoxazole was $7.0 \%, 1.1 \%$ and $9.7 \%$ respectively [24]. Diagnosis and treatment of pneumonia in a ritual mass-gathering situation is a medical challenge requiring rapid decision-making and knowledge of its etiology and susceptibility pattern. Therefore, the findings in this study would help clinicians to choose appropriate antimicrobial therapy for Malaysian hajj pilgrims with respiratory symptoms and would also discourage the indiscriminate use of antimicrobial agents and thus prevent further development of bacterial resistance.

The limitations of this study include incomplete data due to brief contact time during the interview sessions. Two of the isolates were not viable to proceed with antimicrobial susceptibility testing because of repeated subculturing to get pure culture.

In conclusion, the acquisition of $S$. pneumoniae among Malaysian Hajj pilgrims in 2013 was significantly low with the uptake of pneumococcal vaccination. Further large-scale studies with culture-based and PCR-based methods were required for the detection of specific serotypes and genotypes, which is imperative to assess the impact of vaccination and the resistance mechanism. Thus, a better understanding of the epidemiology of $S$. pneumoniae during mass gatherings should be obtained.

Funding: This study was funded by Ministry of Higher Education Malaysia through Long-term Research Grant Scheme (203.PTS.6728003).

Acknowledgments: We gratefully acknowledge Malaysia Airports Sdn Bhd, Sultan Ismail Petra Airport, Kota Bharu, Kelantan and Lembaga Tabung Haji Malaysia for giving permission and providing flights arrival schedules for subjects interview and samples collection at the airport. We appreciate the contributions of three students in Master of Microbiology program; Dr Zety Norfidiyati Ayub, Dr Suhana Hashim and Dr Wan Norliyana Wan Mahmud, who took part in samples and data collection and data transfer into SPSS. We also thank Mrs Rosmaniza Abdullah for her laboratory technical contribution.
Conflict of interest: The authors declare that they have no competing interests.

\section{REFERENCES}

1. Madani TA, Ghabrah TM, Al-Hedaithy MA, et al. Causes of hospitalization of pilgrims in the Hajj season of the Islamic year 1423 (2003). Ann Saudi Med 2006; 26(5):346-51.

2. Memish ZA, Assiri A, Almasri M, et al. Impact of the Hajj on pneumococcal transmission. Clin Microbiol Infect 2015; 21(1):77.e11-8.

3. Benkouiten S, Gautret P, Belhouchat K, et al. Acquisition of Streptococcus pneumoniae carriage in pilgrims during the 2012 Hajj. Clin Infect Dis 2014; 58(4):e106-9.

4. Benkouiten S, Charrel R, Belhouchat $\mathrm{K}$, et al. Respiratory Viruses and Bacteria among Pilgrims during the 2013 Hajj. Emerging Infectious Diseases 2014; 20(11):1821-1827.

5. Centers for Disease Control and Prevention. Updated recommendations for prevention of invasive pneumococcal disease among adults using the 23-valent pneumococcal polysaccharide vaccine (PPSV23). MMWR 2010;59(No.34):11026.

6. Pérez-Trallero E, Fernández-Mazarrasa C García-Rey C, et al. Antimicrobial susceptibilities of 1,684 Streptococcus pneumoniae and 2,039 Streptococcus pyogenes isolates and their ecological relationships: results of a 1-year (19981999) multicenter surveillance study in Spain. Antimicrob Agents Chemother 2001; 45 (12):333440.

7. Felmingham $D$, White $A R$, Jacobs $M R$, et al. The Alexander Project: the benefits from a decade of surveillance. J Antimicrob Chemother 2005; 56 Suppl 2:ii3-ii21.

8. ABCs, Centers for Disease Control and Prevention. 2013. Active Bacterial Core Surveillance Report, Emerging Infections Program Network, Streptococcus pneumoniae, 2012. Available at: http://www.cdc.gov/abcs/reports findings/survreports/spneu12.pdf.

9. Kim SH, Song JH, Chung DR, et al. Changing trends in antimicrobial resistance and serotypes of Streptococcus pneumoniae isolates in Asian countries: an Asian Network for Surveillance of Resistant Pathogens (ANSORP) study. Antimicrob Agents Chemother 2012; 56(3):1418-26.

10. Abraham-Van Parijs, B. Review of pneumococcal conjugate vaccine in adults: implications on clinical development. Vaccine 2004; 22(1112):1362-71.

11. Tashani $M$, Barasheed $O$, Azeem $M$, et al. Pneumococcal Vaccine Uptake Among Australian Hajj pilgrims in 2011-13. Infect Disord Drug Targets 2014; 14(2):117-124. 
12. Malaysian Clinical Practical Guidelines, Academy of Medicine of Malaysia. 2003. Clinical Practice Guidelines, Adult Vaccination. Available at http://www.acadmed.org.my/index.cfm?\&menuid= 67. 2003. Accessed 17 May 2015.

13. Clinical and Laboratory Standards Institute. Performance Standards for Antimicrobial Susceptibility Testing: Twenty-first Informational Supplement M100-S21. CLSI, Wayne, PA, USA, 2011.

14. El-Sheikh SM, El-Assouli SM, Mohammed KA, Albar M. Bacteria and viruses that cause respiratory tract infections during the pilgrimage (Haj) season in Makkah, Saudi Arabia. Trop Med Int Health 1998; 3(3):205-9.

15. Alzeer AH. Respiratory tract infection during Hajj. Ann Thorac Med 2009; 4(2):50-3.

16. Asghar AH, Ashshi AM, Azhar El, Bukhari SZ, Zafar TA, Momenah AM. Profile of bacterial pneumonia during Hajj. Indian J Med Res 2011; 133: 510-3.

17. Mandourah $\mathrm{Y}, \mathrm{Al}$-Radi A, Ocheltree $\mathrm{AH}$, Ocheltree SR, Fowler RA. Clinical and temporal patterns of severe pneumonia causing critical illness during Hajj. BMC Infect Dis 2012; 12:117.

18. Memish ZA, Almasri M, Turkestani A, Al-Shangiti AM, Yezli S. Etiology of severe communityacquired pneumonia during the 2013 Hajj-part of the MERS-CoV surveillance program. International Journal of Infectious Diseases 2014; 25 (0):186-190.

19. Immunizations, C.V. Centers for Disease Control and Prevention. Last update February 22015. Vaccines and Immunizations, Vaccines and Preventable Diseases, Pneumococcal Vaccination:Who Needs It ? Retrieved 17 May 2015. Available at: http://www.cdc.gov/vaccines/vpdvac/pneumo/vacc-in-short.htm.

20. Zhang $Y$, Isaacman DJ, Wadowsky RM, Rydquist-White J, Post JC, Ehrlich GD. Detection of Streptococcus pneumoniae in whole blood by PCR. J Clin Microbiol 1995; 33(3):596-601.

21. Abd Aziz N., Hassan Y., Hashim H., Malik Mansoor S., Abd Shatar A.K.. PHP108 Pattern of Antibiotics Usage in Malaysian Hajj Pilgrim. Value Health 2012; 15(7):A626-A627.

22. Lysenko ES, Ratner AJ, Nelson AL, Weiser JN. The role of innate immune responses in the outcome of interspecies competition for colonization of mucosal surfaces. PLoS Pathog 2005; 1(1):e1.

23. Nuorti JP, Butler JC, Farley MM, et al. Cigarette Smoking and Invasive Pneumococcal Disease. N Engl J Med 2000; 342(10):681-689.
24. Rohani MY, Parasakthi N, Raudzah A, Yasim MY. In-vitro susceptibilities of Streptococcus pneumoniae strains isolated in Malaysia to six antibiotics. J Antimicrob Chemother 1999; 44(6):852-3. 